\title{
Determinants of food security among households in Nigeria
}

\begin{abstract}
Background and Objective: Although the government has demonstrated a commitment to confronting the issue of food security in Nigeria with different policies, the result indicates that the target is far from being realized, as the country is still listed among the hungry and food-insecure nations. More than 50\% of the household income goes to meeting food requirements. This paper was attempted to explore the factors affecting food security status among urban and rural households in Nigeria.

Materials and Methods: Using the econometric method, the study used the food consumption score as a proxy for food security to measure the impact of some determinants of household food security on rural and urban households in Nigeria.

Results: The result of the ordinary least square (OLS) analysis and the multinomial log it models revealed that education, food and non-food expenditures and the number of adults have a significant positive influence on food security. However, age, gender and household size affect food security slightly and negatively. Land size was expected to be positively affect food security but it was insignificant, which can be explained by the land acquisition and ownership system of the country.

Conclusion: The findings of this study suggest that the government needs to intensify efforts for programs that will promote the education of household heads' by improving the access of poor households to formal education, increasing income, increasing social capital and reviewing land ownership policies to allow for the transfer of land to rural house holds. These efforts will create opportunities for improving food security in the country.
\end{abstract}

Keyword: Determinant of household food security; Fixed-effect model; Food access; Food consumption score; General household survey; Household food security 